\title{
Health burden of overweight and obesity: Mortality and years of life lost (YLL) of diseases in Indonesia
}

\author{
Susi Ari Kristina ${ }^{1 *}$ \\ Abdillah Ahsan', \\ Faradiba Faradiba ${ }^{1}$, \\ Shahiroh Haulaini ${ }^{1}$ \\ 1 Department of Pharmaceutics, Faculty \\ of Pharmacy, Universitas Gadjah Mada, \\ Yogyakarta, Indonesia \\ 2 Faculty of Economics and Business, \\ Universitas Indonesia, Jakarta, Indonesia
}

\section{*Corresponding author:}

Susi Ari Kristina

susiari_k@ugm.ac.id
Keywords:

Obesity, attributable fraction, non-communicable diseases, mortality https://www.pharmacy.mahidol.ac.th/journal/ (C) Faculty of Pharmacy, Mahidol University (Thailand) 2021

\begin{abstract}
High prevalence of obesity increased burden from noncommunicable diseases. Our study aimed to estimate the number of death and years of life lost (YLL) diseases related to obesity. The Obesity attributable fraction (OAF) was used to estimate the proportion of each comorbidity attributable to obesity. The number of deaths attributable to obesity was estimated by multiplying the number of patients in each disease category and the OAF. The YLL was calculated by the number of years remaining life and the number of deaths due to overweight and obesity. The mortality attributable to overweight and obesity was estimated at 2,264,593 and 1,414,670 respectively, with the proportions of woman death were $60 \%$ and $72 \%$ of total death due to overweight and obese respectively. The YLL attributable to overweight and obesity was estimated at 67 million and 42 million person-years respectively. Diabetes mellitus and ischemic heart disease were two highest burdens both in the number of death and YLL. Obesity imposes a substantial health burden on Indonesian society especially in term of health burden. In view of a magnitude of the impact of obesity, there is a need for both further research and action at the level of health policy.
\end{abstract}

\section{INTRODUCTION}

The prevalence of obesity is increasing both in developed and developing countries. Epidemiology studies indicate that obesity is a major risk factor for diabetes type 2, cardiovascular diseases, and cancers ${ }^{1,2}$. The high prevalence of obesity, combined with other health risks, makes it a high health burden, which can lead to further incidence, mortality, and economic costs ${ }^{3,4}$. Global Burden of Diseases, Injuries, and Risk Factors Study (GBD Study) has quantified the health loss from diseases and injuries, by age, sex, and risk factors in worldwide population over time, covers 195 countries to project the burden magnitudes ${ }^{5}$. The leading three causes of disability-adjusted life years (DALYs) globally according to this study were ischemic heart disease, cerebrovascular disease, and lower respiratory infections, comprising $16.1 \%$ of all DALYs.

The health impacts associated with obesity is expected to be immense and have a greater impact on developing countries ${ }^{6,7}$. Obesity and its attributable comorbidities caused enormous healthcare impact ranged from an increasing number of deaths, years potential life lost, as well as healthcare costs ${ }^{8,9}$.

According to the World Health Organization (WHO), the global prevalence of obesity has more than doubled between 1980 and $2008^{10}$. In 2008 , Kelly et al estimated that more than 1.4 billion adults aged 20 and over were overweight (a BMI greater than or equal 
to $\left.25 \mathrm{~kg} / \mathrm{m}^{2}\right)^{4}$. Of these overweight adults, 500 million were obese ${ }^{4}$. As a result of lifestyle changes in eating, and lower physical activity, the obesity epidemic affects populations in most countries, including in $\mathrm{Asia}^{7}$.

The epidemiology data and burden of obesity is documented for most developed countries $^{11-13}$. Direct healthcare costs attributable to obesity have been estimated to range from $1.5 \%$ of national health expenditure in Thailand ${ }^{1}$ to $9.8 \%$ in Hong Kong ${ }^{7}$. Estimating the health burden of obesity is critical for healthcare providers, policy makers, and payers. Not only can the data estimate be used to establish priorities for research and health resource use, but it can also be used to improve public awareness of the negative health impacts of obesity.

In accordance with global projection trends, the prevalence of obesity in Indonesia increased more than $70 \%$ between 2010 and $2014^{10}$. According to the WHO global health observatory (GHO) database 2010, $17.3 \%$ of adult Indonesian men and $25.2 \%$ of women were classified as overweight (BMI $25-30 \mathrm{~kg} / \mathrm{m}^{2}$ ), and prevalence of obese (BMI > $30 \mathrm{~kg} / \mathrm{m} 2)$ were $3.1 \%$ and $6.5 \%$ in male and female respectively ${ }^{10}$. Despite this rapid increase in obesity over the last five years, and it is recognized that obesityrelated comorbidities generate high costs $^{14-16}$, few cost analyses have been conducted for Indonesia setting. Previous study focused on healthcare costs in Indonesia noted that treatment cost of comorbidities related to smoking in Indonesia was estimated to be at least USD 2,177 million, approximately $2.5 \%$ of $\mathrm{GDP}^{17}$. Since no empirical study is available in Indonesia for determining obesity-related health burden, our study aims were to estimate the burden of diseases in terms of premature death and years of life lost (YLL) related to overweight and obese among Indonesian adult population.

\section{MATERIALS AND METHODS}

This study was a prevalence-based burden of diseases study. Epidemiological data used in this study were taken from the literature and official Indonesia publications as described below.

\subsection{Obesity and comorbidities}

Obesity was categorized into two categories, as overweight (having a BMI of $25-30 \mathrm{~kg} / \mathrm{m}^{2}$ ) and obese (having a BMI of $30 \mathrm{~kg} / \mathrm{m}^{2}$ or higher). Criteria of comorbidities included in this study were selected based on the degree of disease associated with obesity, the availability of existing information and its relevance to the Indonesia context. The following 10 comorbidities were included in our study: colon and colorectal cancer, pancreas cancer, breast cancer, ovarian cancer, endometrial cancer, diabetes mellitus, hypertension, ischemic heart disease, asthma, and stroke. The number of mortality for each disease was estimated from the Obesity Attributable Fraction (OAF). The attribution of the mortality of comorbidity in the population that is related to obesity ${ }^{18}$, was calculated for each comorbidity using the following formula:

$$
\mathrm{OAF}_{\mathrm{ij}}=\frac{\mathrm{P}(\mathrm{RRij}-1)}{\mathrm{P}(\mathrm{RRij}-1)+1}
$$

$\mathrm{OAFij}=$ Obesity Attributable Fraction, for Body Mass Index (BMI) level (i: BMI $=25.0-29.9 \mathrm{~kg} / \mathrm{m}^{2}$ and j: BMI $>=30 \mathrm{~kg} / \mathrm{m}^{2}$ ) $\mathrm{Pij}=$ Prevalence of obesity at BMI level $\mathrm{i}$ or $\mathrm{j}$ of comorbidity RRij = Relative Risk of comorbidity associated with BMI level i or $\mathrm{j}$

In this study, obesity prevalence (P) was obtained from the WHO global health observatory (GHO) database by country in 2010, where overweight among male and female $17.3 \%$ and $25.2 \%$ respectively. Prevalence of obese were $3.1 \%$ and $6.5 \%$ in male and female respectively ${ }^{10}$ while the Relative Risks (RR) were derived from metaanalyses ${ }^{2}$ which consisted of a prospective cohort study of the general population of countries in Europe or North America, Australia or New Zealand.

\subsection{Mortality and Years Life Lost (YLL) attributable to obesity}

The number of mortality of comorbidities related to obesity was estimated by multiplying sex-and age-specific cancer mortality and OAF. The number of deaths from each comorbidity was obtained from the 2011 WHO mortality data. These mortality rates were estimated based on updated regional data inputs which take into account the greater availability of national death registration data. Projections based on the historically observed relationships of mortality with cause-specific mortality rates as well as economic and social development ${ }^{19}$.

To estimate years life lost (YLL) ${ }^{20}$, we used epidemiological data inputs include the number of deaths that could be attributed to obesity and life expectancy by age group. The data on the total number of deaths from each comorbidity were obtained from the 2011 WHO mortality by specific causes. Obesity attributable 
risk was used to estimate the number of deaths attributable to obesity. We use WHO standard expected years of life in $2011^{21}$ to calculate the years of premature death. The number of years remaining to live was derived from subtracting age of death from "life expectancy". Life expectancy was obtained from the WHO standard expected years of life in 2011. To estimate age-specific YLL each comorbidity we applied the YLL formula as number of obesity attributable deaths multiply by number of years remaining to live.

Table 1. Relative risks for selected comorbidities in obese subjects and Obesity Attributable Fraction (OAF).

\begin{tabular}{|c|c|c|c|c|c|c|c|c|}
\hline \multirow[t]{3}{*}{ Comorbidities } & \multicolumn{4}{|c|}{ RR* } & \multicolumn{4}{|c|}{ OAF (\%) } \\
\hline & \multicolumn{2}{|c|}{ Overweight } & \multicolumn{2}{|c|}{ Obese } & \multicolumn{2}{|c|}{ Overweight } & \multicolumn{2}{|c|}{ Obese } \\
\hline & Male & Female & Male & Female & Male & Female & Male & Female \\
\hline Colon and colorectal cancer & 1.51 & 1.45 & 1.95 & 1.66 & 8.11 & 10.19 & 2.32 & 3.87 \\
\hline Pancreas cancer & 1.28 & 1.24 & 2.29 & 1.6 & 4.62 & 5.70 & 3.12 & 3.53 \\
\hline Breast cancer & & 1.08 & & 1.13 & & 1.98 & & 0.79 \\
\hline Ovarian cancer & & 1.18 & & 1.28 & & 4.34 & & 1.68 \\
\hline Endometrial cancer & & 1.53 & & 3.22 & & 11.78 & & 11.93 \\
\hline Diabetes Mellitus & 2.4 & 3.92 & 6.74 & 12.41 & 19.50 & 42.39 & 12.55 & 41.04 \\
\hline Hypertension & 1.28 & 1.65 & 1.84 & 2.42 & 4.62 & 14.07 & 2.06 & 7.97 \\
\hline Ischemic heart disease & 1.29 & 1.8 & 1.72 & 3.1 & 4.78 & 16.78 & 1.77 & 11.36 \\
\hline Asthma & 1.2 & 1.25 & 1.43 & 1.78 & 3.34 & 5.93 & 1.06 & 4.54 \\
\hline Stroke & 1.23 & 1.15 & 1.51 & 1.49 & 3.83 & 3.64 & 1.26 & 2.90 \\
\hline
\end{tabular}

$* R R$ was retrieved from $G u h D P$, Zhang $W$, Bansback $N$, Amarsi $Z, L B$, Anis AH. The incidence of co-morbidities related to obesity and overweight: A systematic review and meta-analysis. BMC Public Health. 2009;9(88):1-20.

\section{RESULTS}

The overall relative risk estimates and OAFs for obesity and the 10 comorbidities, disaggregated by gender, are presented in Table 1 . OAF estimates indicate that about $12.55 \%$ to $42.39 \%$ of all deaths of diabetes mellitus, $1.77 \%$ to $16.78 \%$ of all deaths of ischemic heart disease, and $11.78 \%$ to $11.93 \%$ of all deaths of endometrial cancer in Indonesia were attributable to obesity.

Estimates of the overall number of deaths of obesity, disaggregated by types of comorbidities, gender, and BMI level are displayed in Table 2. With regard to total death, the three conditions that were found to incur the highest deaths were ischemic heart disease $(1,488,714)$, diabetes mellitus $(1,270,377)$ and stroke $(280,000)$.

As shown in Table 2, the estimated number of deaths attributable to obesity is 3.7 million deaths. The death attributable to obesity was accounted for $1.48 \%$ of total deaths in 2015 . Obesity-related deaths for women were about 2 times higher than for men $(2,392,111$ in women vs $1,287,152$ in men).

Table 2. Number of deaths of comorbidities related to obesity.

\begin{tabular}{lcccccc}
\hline Comorbidities & \multicolumn{3}{c}{ Number of deaths of comorbidities related to obesity } \\
\cline { 2 - 6 } & \multicolumn{3}{c}{ Overweight } & \multicolumn{3}{c}{ Obese } \\
\cline { 2 - 6 } & \multicolumn{1}{c}{ Memale } & \multicolumn{1}{c}{ Total } & Male & \multicolumn{1}{c}{ Female } & Total \\
\hline Colon and colorectal cancer & 53,323 & 66,827 & 120,150 & 15,258 & 25,393 & 40,651 \\
Pancreas cancer & 8,634 & 7,553 & 16,188 & 5,839 & 4,676 & 10,515 \\
Breast cancer & 0 & 44,210 & 44,210 & 0 & 17,601 & 17,601 \\
Ovarian cancer & 0 & 31,800 & 31,800 & 0 & 12,307 & 12,307 \\
Endometrial cancer & 0 & 15,648 & 15,648 & 0 & 15,840 & 15,840 \\
Diabetes Mellitus & 248,433 & 438,012 & 686,446 & 159,898 & 424,033 & 583,931 \\
Hypertension & 60,597 & 95,579 & 156,176 & 26,976 & 54,134 & 81,110 \\
Ischemic heart disease & 379,626 & 577,632 & 957,257 & 140,506 & 390,951 & 531,457 \\
Asthma & 23,095 & 26,911 & 50,006 & 7,345 & 20,623 & 27,968 \\
Stroke & 118,602 & 68,110 & 186,711 & 39,019 & 54,271 & 93,289 \\
Total & 892,311 & $1,372,282$ & $2,264,593$ & 394,841 & $1,019,829$ & $1,414,670$ \\
\hline
\end{tabular}


Table 3. Years of life lost (YLL) of comorbidities related to obesity.

\begin{tabular}{|c|c|c|c|c|c|c|}
\hline \multirow{3}{*}{ Comorbidities } & \multicolumn{6}{|c|}{ YLL } \\
\hline & \multicolumn{3}{|c|}{ Overweight } & \multicolumn{3}{|c|}{ Obese } \\
\hline & Male & Female & Total & Male & Female & Total \\
\hline Colon and colorectal cancer & $1,529,594$ & $2,131,380$ & $3,660,974$ & 437,670 & 809,899 & $1,247,570$ \\
\hline Pancreas cancer & 255,549 & 239,787 & 495,336 & 172,806 & 148,452 & 321,258 \\
\hline Breast cancer & & $1,504,068$ & $1,504,068$ & & 598,809 & 598,809 \\
\hline Ovarian cancer & 0 & $1,077,940$ & $1,077,940$ & 0 & 417,177 & 417,177 \\
\hline Endometrial cancer & 0 & 513,222 & 513,222 & 0 & 519,517 & 519,517 \\
\hline Diabetes Mellitus & $7,188,856$ & $13,381,399$ & $20,570,255$ & $4,626,930$ & $12,954,328$ & $17,581,258$ \\
\hline Hypertension & $1,749,632$ & $2,819,332$ & $4,568,964$ & 778,897 & $1,596,802$ & $2,375,699$ \\
\hline Ischemic heart disease & $10,961,988$ & $17,121,552$ & $28,083,540$ & $4,057,229$ & $11,588,149$ & $15,645,378$ \\
\hline Asthma & 692,797 & 893,854 & $1,586,651$ & 220,327 & 685,010 & 905,336 \\
\hline Stroke & $3,317,203$ & $1,903,921$ & $5,221,124$ & $1,091,319$ & $1,517,071$ & $2,608,390$ \\
\hline Total & $25,695,619$ & $41,586,457$ & $67,282,076$ & $11,385,178$ & $30,835,214$ & $42,220,392$ \\
\hline
\end{tabular}

The three conditions that incur the highest YLL were ischemic heart disease $(43,728,918$ person-years), diabetes mellitus $(38,151,513$ person-years), and stroke $(7,829,514$ person-years). The estimated YLL as a result of obesity-related conditions was 109 million personyears. The YLL incurred by women was 2 times higher than it is in men $(72,421,671$ vs $37,080,797$ person-years) (Table 3 ).

\section{DISCUSSION}

This was the first analysis of health burden related obesity in the Indonesian context, where obesity-attributable mortality was found to be substantial, accounting for $1.48 \%$ of national death in the year $2011^{22}$. Many studies have shown that obesity exerts a significant health and cost burden on a country's health system and productivity ${ }^{8,14}$. In addition, the analysis revealed that YLL associated with obesity were broadly similar, which are in line with the findings of previous studies $7,23,24$.

According to the WHO report, overweight and obese account for $44 \%$ of diabetes mellitus cases, $23 \%$ of coronary heart disease cases, and 7 $14 \%$ of cancer cases ${ }^{25}$. These data in accordance with our findings, which estimated that about $40.5 \%$ of ischemic heart deaths, $34.5 \%$ of diabetes mellitus deaths, $7.5 \%$ of hypertension deaths, and $5.5 \%$ cancers deaths in Indonesia were associated with obesity. Similar findings were previously observed in Mexico populations, revealed that type 2 diabetes mellitus was the main cause of premature death ${ }^{24}$. In accordance with western countries, our study found that cardiovascular disease related to obesity to be the primary leading cause of economic and mortality burden. In line with a previous study in Thailand ${ }^{14}$, considering recent updates on the epidemic of cardiovascular diseases and type 2 diabetes in $\mathrm{Asia}^{7}$, we found that ischemic heart disease is the first leading cause of obesity premature death, followed diabetes mellitus, and stroke associated with obesity.

Furthermore, we found that years of life lost attributable to obesity was substantial. These burden had a health impact equal that of smoking, our results indicate that health burden attributable to obesity are the same as those attributable to smoking, which was estimated at 1,207,845 $\mathrm{YLL}^{26}$. A substantial burden both in mortality rate and YLL was largely concentrated in the overweight population, which possible explanation is the higher prevalence of overweight rather than obese population. Given the rise of obesity in Asia, and the prevalence of related conditions, particularly cardiovascular disease and diabetes mellitus, community intervention programs aimed at changing lifestyle and eating habits to control obesity clearly deserve more attention.

In summary, our findings clearly explain that the effect of obesity on the Indonesia's health burden is substantial, and it potentially affects in escalating health care costs, which are since 2014 all Indonesian people are covered by universal health insurance, and paid by government in Indonesia. It is needed that, a public health campaign targeting obesity epidemic should place emphasis on the impact of obesity on society as well as social responsibility, to effectively tackle obesity in Indonesia.

Some potential limitations of our analysis should be noted. First, we used BMI cut off levels for overweight and obesity that are valid for a Caucasian population and the BMI cut off levels of an Asian population used might be lower for overweight and obesity. This might result in underestimating the burden of disease in Indonesia. Second, we used data from the International Database 
estimation in 2011 to estimate the prevalence of obesity by gender and BMI categories ( 25 - 30 and $\geq 30 \mathrm{~kg} / \mathrm{m}^{2}$ ). The prevalences of each comorbidity are derived from the WHO mortality report 2011. In this study, the prevalence of obesity in 2011 was used to calculate the OAF. As lag times for chronic diseases may differ across persons and diseases and are not exactly known, we might have overestimated the mortality from the impact of obesity as the induction time need for developing comorbidity as well as duration of obesity were not taken into account. We also note that there is some evidence that the risks of selected diseases not included in our analysis including osteoarthritis, gallbladder disease, sleep apnea, and depression may be higher among persons who are obese. Furthermore, due to the unavailability of incidence of disease data in Indonesia, the incidence of noncommunicable diseases associated with obesity was not included in the analysis.

\section{CONCLUSIONS}

Our analysis confirmed that obesity imposes a substantial health burden on Indonesia society. In light of the rapid and continuous increase in obesity prevalence in Indonesia, large-scale research focusing on economic cost of obesity, including health care costs and premature mortality costs would be beneficial. Comprehensive interventions for the healthy lifestyle and prevention of obesity should be regarded as public health concerns in Indonesia.

\section{ACKNOWLEDGMENTS}

The Indonesian Universal Health Coverage is acknowledged for providing raw data needed for analysis. Faculty of Pharmacy Universitas Gadjah Mada is acknowledged for support and local administration.

\section{Conflict of interest}

The authors declared no potential conflicts of interest with respect to the research, authorship, and/or publication of this article.

\section{Funding}

The author(s) received no financial support for the research, authorship, and/or publication of this article.

\section{Ethics approval}

This study was approved by Medical and Health Research Ethics Committee (MHREC) Universitas Gadjah Mada with reference number UGM/MHREC/314/REF/2017.

\section{Article info:}

Received April 1, 2019

Received in revised form January 15, 2020

Accepted June 28, 2020

\section{REFERENCES}

1. Seidell JC, Halberstadt J. The global burden of obesity and thechallenges of prevention. Ann Nutr Metab. 2015;66(suppl 2):7-12.

2. Guh DP, Zhang W, Bansback N, Amarsi Z, L B, Anis $\mathrm{AH}$. The incidence of co-morbidities related to obesity and overweight: A systematic review and meta-analysis. BMC Pub Health. 2009;9(88):1-20.

3. Nguyen DM, El-Serag HB. The big burden of obesity. Gastro Endoscopy. 2009;70(4):752-7.

4. Kelly T, Yang W, Chen CS, Reynolds K, He J. Global burden of obesity in 2005 and projections to 2030. Intl J of Obesity. 2008;32:1431-7.

5. GBD 2016 DALYs and HALE Collaborators. Global, regional, and national disability-adjusted life-years (DALYs) for 333 diseases and injuries and healthy life expectancy (HALE) for 195 countries and territories, 1990-2016: a systematic analysis for the Global Burden of Disease Study 2016. Lancet. 2017;390: 1269-344.

6. Monteiro CA, Moura EC, Conde WL, Popki BM. Socioeconomic status and obesity in adult populations of developing countries: a review. Bull World Health Org. 2004;82:940-6.

7. Hoque ME, Mannan M, Long KZ, Al Mamun A. Economic burden of underweight and overweight among adults in the Asia-Pacific region: a systematic review. Trop Med Intl Health 2016;21(4):458-69.

8. Allender S, Rayner M. The burden of overweight and obesity-related ill health in the UK. Obesity Rev. 2007; 8:467-73.

9. Jia H, Lubetkin EI. The statewide burden of obesity, smoking, low income and chronic diseases in the United States. J Pub Health. 2009;31(4):496-505

10. World Health Organization. Global Health Observatory (GHO) Data: Overweight and Obesity by Country Geneva: World Health Organization; 2015 [cited 2016 February 15]; Available from: http://www.who.int/ gho/ncd/risk_factors/overweight/en/.

11. Sander B, Bergemann R. Economic burden of obesity and its complications in Germany. Eur J Health Econ. 2013;4(4):248-53.

12. Wang YC, McPherson K, Marsh T, Gortmaker SL, Brown M. Health and economic burden of the projected obesity trends in the USA and the UK. Lancet. 2011; 378:815-25.

13. Luo W, Morrison H, de Groh M, Waters C, DesMeules $\mathrm{M}$, Jones-McLean E, et al. The burden of adult obesity in Canada. Chronic Diseases Canada. 2007;27(4):135-44.

14. Pitayatienanan P, Butchon R, Yothasamut J, Aekplakorn $\mathrm{W}$, Teerawattananon Y, Suksomboon N, et al. Economic 
costs of obesity in Thailand: a retrospective cost- of-illness study. BMC Health Services Res. 2014; 14(146):1-7.

15. Finkelstein EA, Trogdon JG, Brown DS, Allaire BT, Kamal-Bahl SJ. The lifetime medical cost burden of overweight and obesity: Implications for obesity prevention. Obesity. 2008;18:1843-8.

16. Rtveladze K, Tim Marsh T, Webber L, Kilpi F, Levy D, McPherson K, et al. Health and economic burden of obesity in Brazil. PLoS ONE. 2013;8(7):e68785.

17. Kristina SA, Endarti D, Wiedyaningsih C, Fahamsya A, Faizah N. Health Care Cost of Noncommunicable Diseases Related to Smoking in Indonesia, 2015. Asia Pac J Pub Health. 2018;1-7.

18. Flegal KM, Panagiotou OA, Graubard BI. Estimating population attributable fractions to quantify the health burden of obesity. Ann Epidemiol. 2015;25(3):201-7.

19. World Health Organization. Global Burden of Disease. Geneva: World Health Organization, 2017.

20. Gardner JW, Sanborn JS. Years of Potential Life Lost (YPLL) What Does it Measure? Epidemiology. 1990; $1(4): 322-9$

21. World Health Organization. Life Tables 2015. 2016 [cited 201624 November]; Available from: http://apps. who.int/gho/data/view.main.60750?lang=en.

22. Ministry of Health. Basic Health Survey Report. Jakarta: Ministry of Health, 2015.

23. Muennig P, Lubetkin E, Jia H, Franks P. Gender and the burden of disease attributable to obesity Am J Pub Health. 2006;96(9):1662-8.

24. Murillo-Zamora E, Raúl García-Ceballos R, DelgadoEnciso I, Garza-Guajardo R, Barboza-Quintana O, Rodríguez-Sánchez IP, et al. Regional-level estimation of expected years of life lost attributable to overweight and obesity among Mexican adults. Glob Health Action. 2016;9:31642.

25. Ng M. Global, regional, and national prevalence of overweight and obesity in children and adults during 1980-2013: A systematic analysis for the Global Burden of Disease Study 2013. Lancet. 2014;384:766-81.

26. Kristina SA, Endarti D, Prabandari YS, Ahsan A, Thavorncharoensap M. Burden of Cancers Related to Smoking among the Indonesian Population: Premature Mortality Costs and Years of Potential Life Lost. Asian Pac J Cancer Prev. 2015;16(16):6903-8. 